Arq. Bras. Med. Vet. Zootec., v.70, n.4, p.1135-1140, 2018

\title{
Avaliação da zinco protoporfirina (ZPP) em ruminantes domésticos
}

[Zinc protoporphyrin (ZPP) evaluation in domestic ruminants]

\author{
J.A. Bombardelli, G.A. Reis, C.G. Lupatini, M.M. Kogika, F.J. Benesi
}

Universidade de São Paulo - São Paulo, SP

\begin{abstract}
RESUMO
Nos sistemas de criação de ruminantes, a anemia crônica pode levar a grandes prejuízos econômicos, sendo decorrente da deficiência de ferro no organismo. Quando este se torna indisponível para ser incorporado à hemoglobina, forma-se um composto denominado zinco protoporfirina (ZPP), que pode ser um marcador precoce para a anemia, útil, portanto, para seu diagnóstico. Porém, para a utilidade dessa mensuração, é necessário que se conheçam os valores normais de ZPP para cada espécie. Assim, foram utilizados 30 bezerros, 30 caprinos e 30 ovinos, todos saudáveis, nos quais foram mensurados esses valores. Essa mensuração foi determinada em amostras de sangue refrigeradas, coletadas com EDTA, obtendo-se valores em hemácias não lavadas e lavadas. A lavagem visou à eliminação de substâncias interferentes nessas medidas. A média da ZPP nas amostras não lavadas foi de $80,9 \mu \mathrm{mol} \mathrm{ZPP} / \mathrm{mol} \mathrm{de}$ heme nos bezerros; 55,09 $\mu \mathrm{mol} \mathrm{ZPP} / \mathrm{mol}$ de heme nos caprinos e 73,76 $\mu \mathrm{mol} \mathrm{ZPP} / \mathrm{mol}$ de heme nos ovinos. Após a lavagem, os valores foram 61,4 $\mu \mathrm{mol} \mathrm{ZPP/mol} \mathrm{de} \mathrm{heme;} \mathrm{43,92 \mu mol} \mathrm{ZPP/mol} \mathrm{de} \mathrm{heme} \mathrm{e}$ $59,36 \mu \mathrm{mol} \mathrm{ZPP} / \mathrm{mol}$ de heme, nos bezerros, caprinos e ovinos, respectivamente. Devido à praticidade da técnica, essa pode ser empregada para a detecção precoce da anemia ferropriva, sendo recomendada a prévia lavagem das hemácias.
\end{abstract}

Palavras-chave: ruminantes, anemia, ferro, zinco, hemoglobina

\begin{abstract}
In ruminant breeding systems, chronic anemia can lead to economic losses, resulting from iron deficiency in the organismo. When iron is unavailable for incorporation into hemoglobin, a compound called zinc protoporphyrin (ZPP) is formed, may be an early marker for anemia and is useful for its diagnosis. However, for this measurement to be useful, it is necessary to know the normal values for the species. Therefore, 30 calves, 30 goats and 30 sheep, all of them healthy, to standardize the values were used. This measurement was determined on refrigerated blood samples collected with EDTA, obtaining values in red blood cells not washed and washed. The washing aimed at the elimination of interfering substances in these measures. The mean of the ZPP in the unwashed samples was 80,9

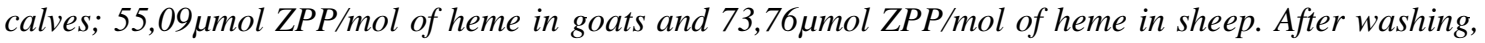

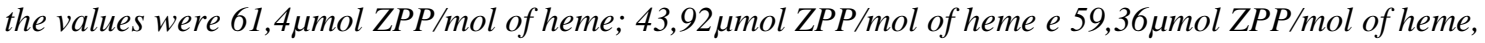
in calves, goats and sheep, respectively. Due to its practicality, the techniquecan be used for the early detection of iron deficiency anemia, recommending the previous lavage of the red blood cells.
\end{abstract}

Keywords: ruminants, anemia, iron, zinc, hemoglobin

\section{INTRODUÇÃO}

A anemia crônica nos animais domésticos afeta grande número de indivíduos de diferentes espécies, ocasionando problemas de caráter econômico, consequentes à redução no ganho de

Recebido em 22 de junho de 2017

Aceito em 11 de outubro de 2017

E-mail: juliana.bombardelli@usp.br peso, à diminuição da produção e/ou da eficiência reprodutiva e, nos casos mais graves, à morte dos doentes (Pugh, 2005). A anemia pode ser decorrente do parasitismo por vermes hematófagos, que ocasionam perda crônica de sangue nas fezes, diminuindo, assim, a reserva de ferro do organismo (Watson e Canfield, 2000). 
As infecções parasitárias são um grande obstáculo ao melhoramento da produção animal, principalmente nos pequenos ruminantes. A deficiência de ferro também pode ocorrer nos animais jovens em fase de crescimento, pois estes têm menores reservas desse componente no organismo (Harvey, 2000).

No sistema orgânico, o ferro é incorporado na protoporfirina IX, um anel tetrapirrólico, para formar a fração heme, que se liga à globina, constituindo-se, assim, a hemoglobina (Alberts et al., 1998; Kaneko, 2000). Quando há indisponibilidade do ferro, o zinco é ligado à protoporfirina IX, formando o composto denominado zinco protoporfirina (ZPP). Essa substituição ocorre predominantemente dentro da medula óssea e a proporção ZPP/heme nos eritrócitos reflete o status de ferro na medula óssea (Labbé et al., 1999). A ZPP é, portanto, um composto que permite identificar a deficiência de ferro antes do desenvolvimento dos sinais da anemia, mostrando-se um marcador precoce e de alta especificidade e sensibilidade para o diagnóstico dessa enfermidade (Mafra e Cozzolino, 2000).

A mensuração da ZPP eritrocitária tem sido usada na medicina humana como um marcador precoce da eritropoiese deficiente de ferro em anemias causadas por doenças renais, bem como por outras afecções que evoluem para a anemia (Labbé et al., 1999; Mafra e Cozzolino, 2000). Assim, indica a potencial possibilidade do uso dessa técnica em medicina veterinária, permitindo a identificação da deficiência de ferro precocemente (Hart e Piomelli, 1981).

Poucos trabalhos relacionados à ZPP são descritos na medicina veterinária. Devido à escassez de dados relacionados a esse tema nas espécies ruminantes domésticas, este trabalho foi desenvolvido com o objetivo de determinar os valores da ZPP em amostras de sangue coletadas em EDTA, comparando-se os valores de ZPP obtidos com e sem lavagem de hemácias. O procedimento de lavagem é recomendado em razão de substâncias fluorescentes que podem estar presentes no plasma e que, portanto, podem interferir nos resultados, elevando os valores de ZPP, assim como citado por Braun (1999).

\section{MATERIAL E MÉTODOS}

Durante o estudo, aprovado pela Comissão de Ética - Ceua/FMVZ/USP - protocolo número 2520/2012, foram utilizados 30 bezerros neonatos da raça Holandesa, 30 caprinos adultos da raça Saanen e 30 ovinos adultos sem raça definida, todos clinicamente sadios, independentemente do sexo. Durante a seleção desses animais, foi realizado o exame físico para verificação do estado geral, sendo avaliadas as funções vitais, o estado de hidratação, as mucosas aparentes e as características das fezes (Pugh, 2005), além de exames complementares para a avaliação do eritrograma, da proteína total plasmática, das taxas de ferro, bilirrubinas e ureia séricos e a análise coproparasitológica das fezes (OPG) (Kaneko, 2000). Os animais que apresentaram qualquer alteração em algum dos exames não foram incluídos no estudo, não sendo realizada a mensuração da ZPP.

As amostras de sangue para essas avaliações foram coletadas por meio de punção da veia jugular externa, usando-se sistema a vácuo com ácido etilenodiamino tetra-acético (EDTA) tripotássico e agulha $(25 \mathrm{~mm} \times 8)$ do sistema Vacutainer ${ }^{\circledR}$. As amostras foram refrigeradas a $4^{\circ} \mathrm{C}$ até o momento do exame, que não ultrapassou três horas desde o momento da coleta, para todas as análises.

As avaliações do eritrograma foram realizadas segundo método e padronização descritos por Birgel (1983) e Jain (1993). A contagem global de eritrócitos foi realizada manualmente em hemocitômetro. $\mathrm{O}$ volume globular foi determinado por meio da microtécnica. A mensuração da taxa de hemoglobina foi efetuada pelo método da cianometa-hemoglobina.

Os índices hematimétricos, o volume corpuscular médio (VCM), a hemoglobina corpuscular média (HCM) e a concentração de hemoglobina corpuscular média (CHCM) foram calculados com base nos valores obtidos para a contagem dos eritrócitos $(\mathrm{He})$, da taxa de hemoglobina (Hb) e do volume globular ou hematócrito (Ht). Nenhum dos animais incluídos no estudo apresentou alterações nesses exames, sendo usados os valores de referência para cada espécie, segundo Meyer e Harvey (2004). 
Para o exame coproparasitológico, as amostras de fezes foram coletadas manualmente da ampola retal, com a utilização de luvas de procedimento de látex. A avaliação utilizada para o exame coproparasitológico foi a contagem de ovos por grama de fezes (OPG), realizada de acordo com a técnica modificada de Gordon e Whitlock (1939). Para serem incluídos no estudo, os animais deveriam apresentar menos de 500 ovos por grama de fezes da superfamília Strongyloidea, e menos de 800 ovos por grama de fezes das espécies do gênero Eimeria. Porém, todos os animais obtiveram baixa contagem de ovos durante o exame, sendo, portanto, incluídos no estudo.

Para as avaliações bioquímicas, as amostras de sangue foram coletadas por meio de punção da veia jugular externa usando-se sistema a vácuo, em tubo siliconizado sem anticoagulante (capacidade para $10 \mathrm{~mL}$ de sangue) e agulha para múltiplas coletas $(25 \mathrm{~mm} \quad \mathrm{x} \quad 8)$ do sistema Vacutainer®. Após a coagulação do sangue e a retração do coágulo, os tubos foram centrifugados a 3500rpm, por 10 minutos, com a finalidade de se separar o soro sanguíneo. O soro assim obtido das amostras foi congelado para a posterior avaliação das bilirrubinas, da ureia e do ferro séricos. A determinação da proteína total plasmática (PTP) foi feita por meio de refratometria. Todos os animais incluídos na pesquisa apresentaram valores para esses exames dentro das referências propostas por Meyer e Harvey (2004).

Os valores das concentrações da ZPP eritrocitária foram determinados nas amostras de sangue coletadas com EDTA e mantidas sob refrigeração. A leitura da amostra foi realizada em triplicata e a média aritmética das medições foi considerada como o valor em $\mu$ mol de $\mathrm{ZPP} / \mathrm{mol}$ de heme do animal avaliado.

A determinação da ZPP foi realizada duas vezes em cada amostra de sangue, uma com o sangue in natura e a outra submetida à lavagem das hemácias para eliminação de fatores de interferência. Para a lavagem, foram adicionados $500 \mu \mathrm{L}$ de solução fisiológica a $500 \mu \mathrm{L}$ de sangue, sendo a suspensão centrifugada por 10 minutos em 3000rpm. O sobrenadante foi descartado e $500 \mu \mathrm{L}$ de solução fisiológica foram adicionados ao botão de hemácias. A solução foi ressuspendida e novamente centrifugada. $\mathrm{O}$ procedimento foi repetido por três vezes.
A mensuração da ZPP eritrocitária foi realizada com preparação de amostras, com o uso de kit comercial, e a leitura da amostra foi feita utilizando-se o hematofluorômetro (ProtoFluor ${ }^{\circledR}$ Z Hematofluorometer: Helena Laboratories Beaumont, Texas, USA), por meio do qual foi induzida a excitação de luminosidade em uma ou duas camadas de eritrócitos presentes em uma gota de sangue total, disposta sobre uma lâmina transparente, especialmente preparada para servir de suporte no interior do aparelho. Para tanto, foram adicionadas ao sangue, previamente, duas gotas do reagente, que desencadeou a emissão de fluorescência correspondente à quantidade de ZPP presente na amostra em $\mu$ mol de $\mathrm{ZPP} / \mathrm{mol}$ de heme.

Foi realizada a análise descritiva dos resultados, com interpretação quantitativa, sendo apresentados os valores encontrados, suas médias, medianas, desvios e erros-padrão. Para a realização da análise, foram utilizados os programas estatísticos Instat $®$ e Minitab®. Por terem sido realizadas as análises estatísticas em momentos diferentes para as três espécies, foram utilizados diferentes testes de verificação de normalidade, sendo o teste de Anderson-Darling para a espécie caprina e o de KolmogorovSmirnov para as espécies ovina e bovina. Em caso de distribuição não gaussiana, adotou-se o teste não paramétrico de Wilcoxon para a análise.

\section{RESULTADOS}

Os exames físicos e complementares realizados foram utilizados para verificar a higidez dos animais que foram incluídos no estudo. Os animais que apresentaram alguma alteração em exame físico ou nos exames complementares não foram incluídos no estudo e não foi realizada a mensuração da ZPP.

Após a preparação das amostras para mensuração da ZPP com o reagente, elas foram lidas no hematofluorômetro em triplicata e o valor adotado para cada amostra foi a média aritmética das três leituras em $\mu \mathrm{mol} / \mathrm{mol}$ de heme. Os resultados dos valores das médias aritméticas da ZPP eritrocitária para cada espécie analisada, assim como as medianas, desvios-padrão, errospadrão, valores mínimos, máximos e valor de $\mathrm{P}$ no teste de normalidade encontrados, são exibidos na Tab. 1. 
Tabela 1. Valores de médias, medianas, desvios-padrão, erros-padrão, valores mínimos, máximos e valor de $\mathrm{P}$ no teste de normalidade encontrados durante a análise das amostras com hemácias não lavadas e lavadas

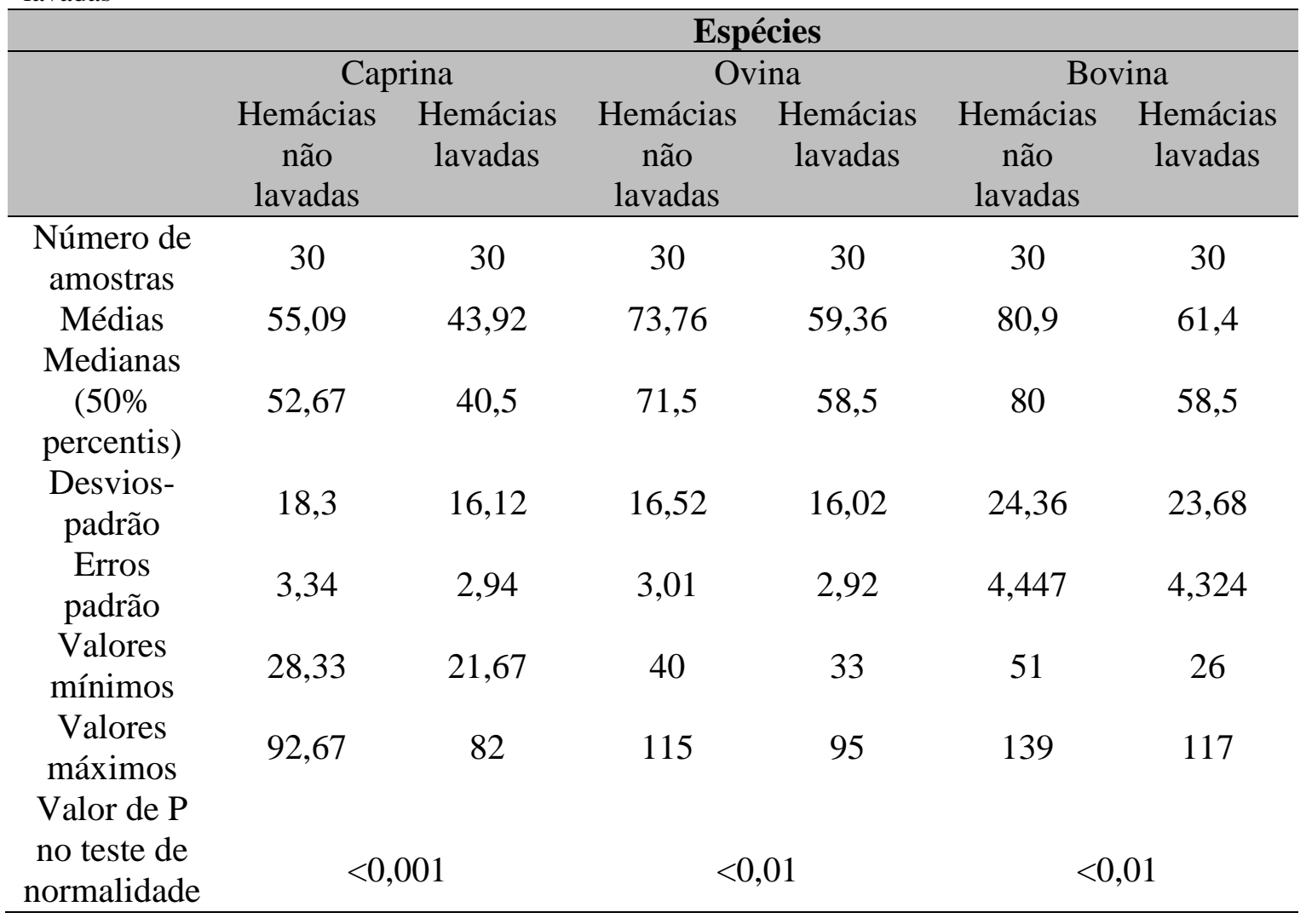

$\mathrm{Na}$ espécie caprina, foi aplicado o teste de normalidade de Anderson-Darling para avaliar se os valores das variáveis encontrados apresentavam distribuição normal. Verificou-se que os valores de ZPP em amostras não lavadas e após lavagem não seguem uma distribuição normal. Assim, por meio do teste não paramétrico de Wilcoxon, verificou-se um resultado que indica que essa diferença entre os valores de hemácias lavadas e não lavadas é estatisticamente significativa $(\mathrm{P}<0,001)$. Nas espécies ovina e bovina, o teste de normalidade de Kolmogorov-Smirnov permitiu verificação de que os resultados obtidos apresentaram distribuição normal. Ao se compararem as médias de ZPP eritrocitária obtidas na mensuração das amostras de sangue total e daquelas com suspensão de hemácias lavadas, verificou-se também, assim como na espécie caprina, a existência de diferença estatística entre elas (teste T-pareado: $\mathrm{P}<0,01$ ).

\section{DISCUSSÃO}

Diversas análises podem ser utilizadas para a avaliação de ferro no organismo em seus diferentes compartimentos (hematócrito, hemoglobina, ferritina e saturação da transferrina), porém inexiste um teste único que diagnostique adequadamente a deficiência de ferro, uma vez que cada uma dessas avaliações considera uma diferente etapa do metabolismo desse componente (Labbé et al., 1999), sendo a determinação de ZPP considerada, até o momento, como um dos melhores indicadores da inadequada eficiência de eritropoiese decorrente dessa deficiência (Labbé, 1992; Braun, 1999).

A mensuração da ZPP permite a identificação da deficiência de ferro antes do desenvolvimento da anemia, pois, quando ele é deficiente para a eritropoiese, a síntese do grupamento heme é alterada e a ZPP é formada, ocorrendo esse processo tanto em humanos quanto em animais (Hart e Piomelli, 1981). A aplicação de qualquer 
exame complementar requer o estabelecimento de seus valores de variação fisiológicos, considerando a espécie em análise.

Com o uso do hematofluorômetro, foi possível a mensuração da ZPP dos animais avaliados, sendo essa análise realizada em triplicata para eliminar possíveis erros durante a leitura, como a presença de bolhas ou sujidades na lâmina, que interfeririam no resultado, já que este é dado por emissão de fluorescência. $\mathrm{Na}$ maioria dos animais, não houve diferença entre as leituras, e essas diferenças, quando encontradas, foram muito pequenas. Assim, tomando-se os devidos cuidados, não há diferença nos resultados do exame de um mesmo animal.

Foi realizada a lavagem das amostras após a obtenção dos resultados para amostras não lavadas, sendo verificado que, após a lavagem, os valores encontrados foram menores que aqueles obtidos com hemácias não lavadas para os três grupos de animais avaliados. Isso mostra que existem substâncias que interferem na leitura da ZPP, demonstrando-se a importância do procedimento de lavagem. É válido ressaltar a possibilidade de a ZPP mensurada ser alterada em concomitância com valores aumentados de bilirrubina sérica ou outras substâncias, como a ureia, assim como em casos de uso de vitaminas do complexo B, que podem gerar valores falsamente aumentados da ZPP (Louro e Tutor, 1994).

O confronto desses resultados na medicina veterinária, especialmente em ruminantes, não foi possível pela ausência de dados na literatura para esses espécimes. Nos felinos e nos humanos, foi constatado que essa avaliação seria uma possibilidade para o diagnóstico da intoxicação por chumbo (Hawke et al., 1992; Ambrogi et al., 1996). Nos humanos, os valores encontrados são menores que os encontrados nas espécies de ruminantes estudadas, pois, de acordo com Shifman e Finley (1981), os valores normais de ZPP são de 25 a $57 \mu \mathrm{mol} \mathrm{ZPP/mol} \mathrm{de}$ heme. Para a espécie humana, Hastka et al. (1993) referem que valores acima de $40 \mu \mathrm{mol}$ $\mathrm{ZPP} / \mathrm{mol}$ heme são indicativos de distúrbios no metabolismo do ferro. Já em caninos, foi encontrado o valor de $56 \pm 2 \mathrm{nmol} / \mathrm{mol}$ de heme por Ambrogi et al. (1996), sendo esse valor mais próximo aos valores mensurados em ruminantes. Apesar de a ZPP não refletir o estoque de ferro como um todo, é considerada como uma prova altamente sensível e específica de deficiência de ferro absoluta, sendo sugerido como um teste de rotina (Labbé et al., 1999). A possibilidade de se obterem valores específicos para os ruminantes favorece a utilização dessa variável na avaliação dos processos anêmicos em que a deficiência de ferro é um fator importante, uma vez que a mensuração da ferritina não é acessível como avaliação de rotina, por se tratar de um método de radioimunoensaio do tipo ensaio de imunoabsorção enzimática (ELISA) espécie-específico. Em contraposição, a hematofluorometria é um método de uso fácil, rápido e não oneroso, que requer uma quantidade pequena de sangue para sua realização (Braun, 1999; Labbé et al., 1999).

Essa técnica ainda é pouco empregada em medicina veterinária, uma vez que é necessário que seja estabelecido, como ora se faz, um padrão de referência com o intervalo de normalidade para a espécie a ser avaliada. Há potencial para novos estudos determinando-se a ZPP eritrocitária, pois existem várias afecções que acometem ruminantes e que ocasionam o desenvolvimento de anemia. Processos inflamatórios também podem resultar em elevação da ZPP, possivelmente por inibição da enzima ferroquelase e, consequentemente, pela não ligação do ferro com a protoporfirina (Braun, 1999). Para tornar esse método rotineiro na clínica veterinária, há a necessidade de realização de outras investigações sobre o tema, a fim de de verificarem outras possíveis interferências que causem alterações em sua mensuração.

\section{CONCLUSÕES}

Com base nos resultados obtidos, pode-se concluir que, por meio de uma técnica simples, puderam ser determinados os valores da ZPP eritrocitária em caprinos, ovinos e bezerros neonatos clinicamente sadios, sendo possível a sua utilização como marcador precoce na detecção da anemia ferropriva nessas espécies, tomando-se com base de variação fisiológica os resultados obtidos e apresentados. No entanto, para tal finalidade, é recomendável que seja realizada a lavagem das hemácias antes da mensuração da ZPP, devido à presença de substâncias interferentes no plasma dos animais ruminantes. A técnica pode ser recomendada 
como método rotineiro, sendo, no entanto, necessária a realização de outras investigações sobre o tema, que contemplem não só o aumento da amostragem, como também outras possíveis influências fisiológicas, como evolução etária, sexo, raças, nutrição e outras condições causadoras da deficiência de ferro.

\section{REFERÊNCIAS}

ALBERTS, B.; BRAY, D.; JOHNSON, A. et al. Fundamentos de biologia celular. Porto Alegre: Artmed, 1998. p.173-174.

AMBROGI, C.; CARDINI, G.; BALDI, S.B. et al. Delta-aminolevulinic acid dehydratase and zinc protoporphyrin in very low lead exposure pets: a community study. Vet. Human. Toxicol., v.38, p.336-339, 1996.

BIRGEL, E.H. Hematologia clínica veterinária. 2ed. In: BIRGEL, E.H.; BENESI, F.J. Patologia clínica veterinária. São Paulo: Sociedade Paulista de Medicina Veterinária, 1983. p.2-62.

BRAUN, J. Erytrocyte zinc protoporphyrin. Kidney Int., v.55, Suppl., p.57-60, 1999.

GORDON, H.M.C.L.; WHITLOCK, H.V. A new techineque for counting nematode egg in sheep feces. J. Counc Sci. Ind. Res., v.12, p.5052, 1939.

HART, D.; PIOMELLI, S. Simultaneous quantitation of zinc protoporphyrin and free protoporphyrin in erythrocytes by acetone extraction. Clin. Chem., v.27, p.220-222, 1981.

HARVEY, J.W. Microcytic anemias. In: FELDMAN, B.V.; ZINKL, J.G.; JAIN, N.C. Schalm's veterinary hematology. Philadelphia: Lippincott Williams\& Wilkins, 2000. p.20002009.

HASTKA, J.; LASSERE, J.J.; SCHWARZBECK, A. et al. Zinc protoporphyrin in anemia of chronic disorders. Blood, v.81, p.1200-1204, 1993.
HAWKE, C.G.; MADDISON, J.E.; POULOS, V. et al. Erythrocyte protoporphyrins concentrations in clinically normal cats and cats with lead toxicity. Res. Vet. Sci., v.53, p.260-263, 1992.

JAIN, N.C. Examination of the blood and bone marrow. In: Essentials of veterinary hematology. Philadelphia: Williams \& Wilkins, 1993. p.1-18.

KANEKO, J.J. Hemoglobin synthesis and destruction. In: FELDMAN, B.V.; ZINKL, J.G.; JAIN. N.C. Schalm's veterinary hematology. Philadelphia: Lippincott Williams \& Wilkins, 2000. p.129-139.

LABBÉ, R.F. Clinical utility of zinc protoporphyrin. Clin. Chem., v.38, p.2167-2168, 1992.

LABBÉ, R.F.; DEWANJI, A.A.; McLAUGHLIN, K. Observation on the zinc protoporphyrin/heme ratio in whole blood. Clin. Chem., v.45, p.146-148, 1999.

LOURO, M.O; TUTOR, J.C. Hematofluorometric determination of erythrocyte zinc protoporphyrin: oxygenation and derivatization of hemoglobin compared. Clin. Chem., v.43, p.369-372, 1994.

MAFRA, D.; COZZOLINO, S.M.F. Zinco protoporfirina como parâmetro de deficiência de ferro na insuficiência renal crônica. J. Bras. Nefrol., v.22, p.152-156, 2000.

MEYER, D.J.; HARVEY, J.W. Veterinary laboratory medicine: interpretation \& diagnosis. 2.ed. Philadelphia:Sauders, 2004, 351p.

PUGH, D.G. Clínica de ovinos e caprinos. São Paulo: Roca, 2005. p.513.

SCHIFMAN, R.B.; FINLEY, P.R. Measurement of near normal concentrations of erythrocyte protoporphyrin with the hematofluorometer: influence of plasma on "front-surface illumination" assay. Clin. Chem., v.27, p.153156, 1981.

WATSON, A.D.J.; CANFIELD, P.J. Nutricional deficiency anemias. 5.ed. In: FELDMAN, B.F. et al. Schalm's veterinary hematology. Philadelphia: Lippinott Willians \& Wilkins, 2000. p.190-195. 